Brit. J. industr. Med., 1953, 10, 51.

\title{
AGE AND INDUSTRIAL ACCIDENT RATES
}

\author{
BY \\ H. F. KING and D. SPEAKMAN \\ From the Nuffield Research Unit into Problems of Ageing, Cambridge Psychological Laboratory
}

(RECEIVED FOR PUBLICATION NOVEMBER 6, 1952)

During the last 50 years, and especially since the first world war, much work has been carried out on the causes and results of industrial accidents, but until Newbold's study (1926) few attempts had been made to separate the various possible direct influences of ageing. From her work and from that of later investigators has come the current view that the accident rate declines steadily as age advances, though not all of the relevant studies support this view and some appear to contradict it. In this review we have attempted to show that at least some of the differences of interpretation appear to be due to the methods of recording used or to the types of work studied, and it is possible that some of the anomalies could be explained if data were suitably collected.

\section{Survey of Previous Studies}

The work done before 1926 has been summarized by Newbold (1926), and generally indicates a fall in accident frequency with age. Newbold collected records of accidents occurring in many departments in 22 factories, the data for each department being kept separately. In every group, except one of young women, there was a downward trend with increasing age, although in a few instances workers over 60 showed a slight upward trend. The relative effects of age and length of service were measured statistically and age was shown to be the more important; there were, however, few new employees in the groups. The work of Vernon and Bedford (1928), and of Vernon, Bedford, and Warner (1931) on compensated accident rates for several thousand coal miners demonstrated a rise in frequency at ages above 40 for coal face workers, but a peak rate in the under-20s for other underground men. Barkin's study (1933) of 282 compensated factory accidents showed a decline in frequency as age advanced, but there was a slight rise at ages above 60 .

Vernon (1936) quotes various studies supporting the view that accident frequency declines with age, but shows that rates are much affected by the inexperience of new workers. Kossoris (1940) examined disabling and compensated injuries in several large communities. In the main there was some tendency for frequency to decline with age, but in one community where exposure was equated for all age groups the frequency was lowest in the 35-39 group and rose with age thereafter. Data collected from 700,000 households relating to non-fatal industrial accidents which had occurred in the previous 12 months were used by Klebba (1941) to demonstrate that the frequency of accidents causing more than six days' absence declined with age among non-manual, but increased markedly among manual, workers.

Mann (1944), observed a decline in frequency of all reported accidents with age among males at an ordnance depot but a rise above the age of 35 among females. Whitlock and Crannell (1949) were unable to demonstrate any significant age difference between 100 steel workers who had major accidents and an accident-free control group. Sutherland, Harris, and Smithers (1950) demonstrated a decline with age in the frequency of all accidents reported to the first aid posts among 4,000 factory workers, the decline being marked up to 25 and more gradual at higher ages. The rate for all employees at a motor works was at a maximum in the 25-34 group and declined rapidly at ages above 45 (Paviere, 1951). However, Heinrich (1950) concludes that although the studies he reviewed indicated a fall in accident frequency wi $\mathrm{i}^{\mathrm{h}} \mathrm{h}$ age, the available data have serious limitations.

Newbold (1926) also gave various figures relating to the duration of disability resulting from accidents and the fatality rate and these indicated a consistent increase with age in both instances. Brundage (1927), who studied 2,200 male electrical workers, found that among these the number of days lost per absence as a result of accidents at 
work increased with age, but that the annual number of absences per 1,000 workers was around 80 for all age groups except the over-55s, for whom it was only 56. A number of later studies have also confirmed the finding with regard to length of disability, among them being those of Vernon and Bedford (1928), Stevens (1929) for some 5,000 compensation cases, Vernon and others (1931), and Klebba (1941). Using three separate sets of data, Kossoris (1940) showed that the frequency of deaths and of permanent impairments per 1,000 injuries, as well as length of disability, increased with age. In a later paper Kossoris (1948) reports that among 18,000 factory workers the frequency of disabling injuries was not related to age, but the frequency of non-disabling injuries showed a steady decline from the 25-29 age group upwards.

It will be seen that there is general agreement as to the effect of age upon the severity of injuries incurred through accidents but the effect on accident frequency is much less certain, and so the remainder of this article is primarily concerned with accident frequency.

\section{Criterion of Accidents}

The authors surveyed base their arguments not on the incidence of accidents as such but on the incidence of accidents which led to injuries. While this is perhaps inevitable for practical reasons, not only is there no account taken of those accidents which result only in spoilt work with no injury to the operator, but the differences in criteria of what constitutes an injury make it not only difficult but hazardous to integrate the results of the various studies in a meaningful fashion. For instance, data based on compensated injuries are likely to be complicated in the following ways. (1) A fixed duration of absence from work following injury is required to qualify the worker for compensation, and the duration varies from one country or state to another. Also, since older workers take longer to recover than do younger workers, a given physical injury is likely to produce more cases of compensation amongst older workers. (2) There is likely to be selection in favour of large organized industries and at the expense of workers and bodies not covered by the Workmens Compensation Acts. This point has been commented upon both by Kossoris (1940) and by Klebba (1941), the latter obtaining from an analysis of U.S. Public Health Survey data results which were at variance with those given by State agencies, sick benefit organizations, and insurance companies, and attributed the difference to the limited coverage of compensation sources. (3) The various age groups are not usually equated for exposure in terms of the length of time they were actively employed during the period of the study.

While statistics relating to serious injury are open to question on the grounds of the statutory requirements for their inclusion in compensation data, statistics of minor injuries, unless they are very carefully collected may, as both Newbold and Sutherland and others (1950) have pointed out, be incomplete when they relate to older workers.

A study of visits to factory health clinics for the relief of minor aches and pains-headaches, colds, digestive discomforts-shows a peak in the late $20 \mathrm{~s}$ and early 30s followed by a steady fall in the number of attendances with age (Kossoris, 1948). Colds, bronchitis, indigestion, and biliousness have, however, been held to increase with age from the early 30 s, while the incidence of headaches reaches its peak about the age of 35 (Fig. 1), and varies

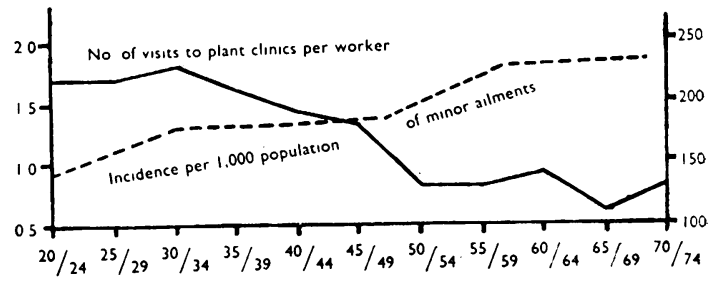

FIG. 1.-The continuous line represents number of visits to plant clinics per worker, on account of minor bodily ailments ; the broken line represents the incidence per 1,000 population of colds, sore throat, bronchitis and chest colds, indigestion, and headache (Collins, 1935).

little till the age of 60 (Collins, 1935). Assuming that the two samples are comparable as regards physical conditions, this finding suggests that some minor bodily discomforts which are reported by younger people are not reported by older. This may be because of fear of discrimination; because of a gradually formed indifference to lesser pains built up over many years' experience of injury ; because of a possible tendency for persons to report only the first or the first few minor injuries ; or because of possible differences in the outlook of earlier generations towards industrial hygiene. Whatever the reason, it is apparent that the subjective attitudes of people in different age groups ought to be taken into account when interpreting accident data based on systems of voluntary reporting.

\section{Occupation}

If the current criteria of what constitutes an accident leave much to be desired, the tendency to collect data on accident rates without reference to specific occupations may be equally misleading. 
When, as is often the case, data from a number of factories, or even from many jobs in one factory, are pooled to give a table of accident rates at different ages, a decline in rate with age could as easily mean that older people are engaged upon less hazardous jobs as that accident liability decreases with age. There are, in fact, a number of strong indications that the age distributions of employees in various occupations do show considerable differences. Evidence was provided by Vernon and Bedford (1928) for coal miners, and for numerous occupations by Belbin and Sewell (1949), a summary of whose work is given by Welford (1951). The latter investigators further show that at least some of these differences are characteristically related to the requirements of the job.

The figures given by Mann (1944) show the wide variation with occupation in the number of accidents per person among workers at an ordnance depot (Table 1). Unfortunately, the data available are

TABLE 1

ACCIDENTS PER PERSON IN DEPARTMENTS OF AN ORDNANCE DEPOT CALCULATED FROM FIGURES GIVEN BY MANN (1944) FOR A FOUR-MONTH PERIOD

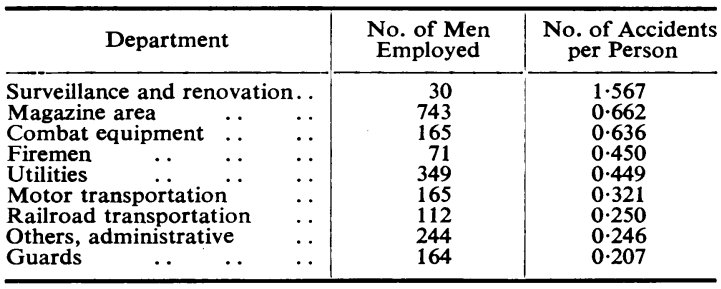

insufficient to indicate whether these differences in liability are associated with the age of the workers. However, Stevens (1929) pointed out that a large number of low-hazard occupations such as those of watchman, sweeper, and so on, were mainly filled by men over 50, and Klebba (1941) also remarked upon the influence exerted on accident frequencies by this tendency for older workers to occupy lowhazard jobs.

Any attempt to assess the influence of age on accident rates, using a mass of data collected from many operations, ignores such differences in age distribution related to the degree of accident hazard and by-passes the important question of selective influences in the production of the agestructure of a working population under study. The study by Newbold (1926) appears to stand alone in that particular care was taken to choose departments where all the employees were on the same type of work, even if this involved restricting the study to one or two departments in a whole factory, and separate rates were calculated for each department.
Even so, there are still difficulties : the samples of workers obtained by this procedure included only a small number of older people ; secondly, as Heinrich (1950) has observed, there may still be small differences in the work done, and important differences in the design of the machines or in working conditions. It is impossible to say at present how far these points are in fact of importance in the study of age variations in accident rates : what is clear is that the subject demands a detailed approach rather than attempts at an overall assessment.

\section{Age and Experience}

The first attempt to measure the relative contribution of age and experience as determinants of accident liability was made by Newbold (1926). The partial correlations which she calculated showed that when age was held constant the original association between length of service and accidents almost disappeared, but when length of service was held constant, the association between age and number of accidents remained almost unchanged. By contrast, Ghiselli, Brown, and Minium (1946) in a survey of street car motormen in Chicago found that when experience was held constant, the relationship between accidents and age was practically zero.

In criticizing Newbold's results, both Newbold herself, and later Vernon, pointed out that experience in this case only referred to the time spent in that particular factory, and not to any previous experience elsewhere ; also Newbold's samples contained very few new entrants, who show a high accident rate, and, as Vernon has pointed out, are largely responsible for her negative relation between accident rate and experience. In fact the data relating to length of service surveyed by Vernon (1936) make it fairly clear that the relation between experience and accident rate is more properly a relationship between "lack of experience and accident rate". With increasing experience the accident rate falls rapidly at first-possibly while the job is being learnt-and varies comparatively little thereafter. The accident rate then, is likely to be dependent upon the rate of labour turnover. Where this is low, and there are few new entrants, it is probable that there would be relatively little relationship between experience and accident rate, particularly in a short-term study. Conversely, where one finds an equally high rate of turnover amongst all age groups, one would expect also to find in a short-term study a very strong relationship between accident rate and experience, and little relationship with age, once experience was partialled out. This kind of relationship might be 
able to explain the apparent contradictions between the results of Newbold, and of Ghiselli, Brown, and Minium, but the published data are unfortunately not sufficient to say definitely whether this is so.

In a large scale survey the general effect of this relation between inexperience and liability to accidents would be to increase the accident rate of the younger age groups, both because they have the greatest number of new entrants, and because it has been claimed that younger age groups tend to have a greater turnover than older (Kitson, 1925; Greystoke, Thomason, and Murphy, 1952). Thus in terms of apparent safety the older would have an advantage over the younger; on the face of it, due to the result of their greater age but in reality due to the effects of labour turnover causing lack of experience in the younger age groups.

A further difficulty in the assessment of the relative roles of age and experience is, as has been contended by Ghiselli and Brown (1948), that the more experienced groups of workers may have been selected in terms of the safety of their performance. Such selection, it is claimed, would prevent compliance with the basic assumptions of the partial correlation method. Certain employees may be moved, by the firm or at the employees' own request, on to other work on account of inability to perform the task, or of incurring a high accident rate, while, for various reasons, other employees may leave the industry altogether. Apart from this it must be remembered that accidents themselves are taking a yearly toll of workers from industry in permanent injuries or deaths. Though it is possible that this gradual elimination may act impartially, if it is true that some people are more accident prone than others, it is likely that these will be removed and that those who will be left will be those who have fewer accidents.

\section{General Physical and Physiological Conditions}

Besides the many problems involved in the collation and analysis of data, in such studies some attempt should be made to assess the importance of the interrelation of various changes in the human organism that occur with age with characteristics of the working environment, by themselves neutral, but in terms of these changes, inimical.

Though it appears that some impairment in function may occur with increasing age without causing an equivalent impairment in performance (Welford, 1951), deterioration beyond a certain point will clearly render many tasks either impossible or highly dangerous. Thus many of the functions which would be supposed to be necessary for efficient driving skill begin to decline either in the early 30 s or before, while safety in terms of millions of miles driven per accident is low in the 20s and reaches a peak somewhat later, at the age of 45-50. Beyond this age, however, the road accident rate increases with age very rapidly (DeSilva, 1938). One example of a deteriorating function which may be involved in this increase is that of visual performance. Thus Selling (1944) found that of 35 accident-prone drivers over 65 years of age, all had imperfect vision.

The relation of visual defects to accident rates in a general industrial sample has been shown by Kuhn (1943), and the enormous quantitative increase in visual defects with age has been shown by Mayer (1937). How far these findings are related is of course speculative, but there appear to be good reasons for supposing that a study of accident rates related to deteriorating visual ability might be fruitful. Visual acuity decreases in older people (Weston, 1948) but it is also dependant upon the degree of illumination in which the stimulus is exposed. Poor illumination, which would therefore adversely affect older people, might result in their exposing themselves to a greater hazard when working on grinding or turning processes, since " accidents due to foreign bodies-such as metal particles and emery powder-getting into the eye were found to be especially influenced by lighting, apparently because the workers tend to bend nearer their work when the light is poor, and so expose their eyes more freely" (Vernon, 1936).

It is important to recognize here that the so-called visual defects of older people may be of two types : defects of peripheral organs and central defects of perception. Only the first kind would be revealed by physical examination of the eye.

Effects of Fatigue.-Vernon and Bedford (1928) showed that accident frequency increased with age among miners, and concluded that this was probably due to the arduous nature of the coal miner's work. A later study (Vernon and others, 1931) showed that the relationship of accident rate to age varied with the temperature conditions under which the miners worked. At temperatures below $70^{\circ}$ there was a general tendency for the accident rate to fall with age ; at temperatures over $70^{\circ}$ there was a marked rise with age from 35 years of age upwards. Vernon (1936) interpreted these findings in the following words :

"Accidents tend to diminish with age because the older men are more skilful and more careful than younger men, but on the other hand they are more easily fatigued, and fatigue may lead to accidents."

In support of this view it should be pointed out that Vernon and Bedford (1928) found that the increase in the accident rate of the older age group 
was greater in the years $1927-28$ when an eight-hour shift was worked than during 1923-24 when a seven-and-a-half-hour shift was worked. Such research as there is on the relation between fatigue and age (Simonson, 1947) confirms Vernon's view that older people are more susceptible to muscular fatigue than younger, while the greater depression of fusion frequency of flicker attributed to older subjects after tiring exercise (Simonson, 1947) suggests that some psychological functions may be more affected by fatigue as age advances. Whether age brings an increased susceptibility to mental fatigue which might affect the capacity to make judgments or anticipate contingencies is a question that requires investigation.

Falls and Lapses.- Sheldon (1948), in a survey of old people living in Wolverhampton, stressed the appearance in old age of such symptoms as vertigo and sudden falls. Statistics of falls, such as are contained in the reports of the Registrar General of England and Wales and in the public health reports in the U.S.A., all show a very marked rise in frequency in the older age groups. Where risk of falls is present either because of slippery floors or the use of raised surfaces or ladders, the accident rate for older
TABLE 2

ANNUAL LOSS OF TIME PER PERSON ON A FACTORY PAY-ROLL AS A RESULT OF WORK ACCIDENTS COMPUTED FROM DATA BY BRUNDAGE (1927) FOR 1922-24

\begin{tabular}{c|c|c|c|c|c}
\hline Age Group & $15-24$ & $25-34$ & $35-44$ & $45-54$ & $\begin{array}{c}55 \text { and } \\
\text { over }\end{array}$ \\
\cline { 1 - 5 } $\begin{array}{c}\text { Mean annual days } \\
\text { of disability } .\end{array}$ & $\begin{array}{c}0.992 \\
520\end{array}$ & $\begin{array}{c}1.336 \\
710\end{array}$ & $\begin{array}{c}1.483 \\
541\end{array}$ & $\begin{array}{c}1.964 \\
311\end{array}$ & $\begin{array}{c}1.867 \\
141\end{array}$ \\
\hline
\end{tabular}

people is likely to be increased, and the accidents sustained likely to be more severe (Fig. 2).

\section{Length of Absence}

The general agreement on the increase in the severity of accidents with age indicates that the liability involved in the employment of older workers cannot be expressed in terms of accident frequency only. Even if there is a fall in the accident rate with age when the variable factors discussed earlier are eliminated, this may be outweighed, in terms of total time lost, because of the longer absence per injury of the older workers. This point is illustrated by Brundage (1927), who calculated the annual loss of time resulting from accidents at work as a rate per employee of the factory concerned (Table 2). Table 2 shows a general increase with age in the

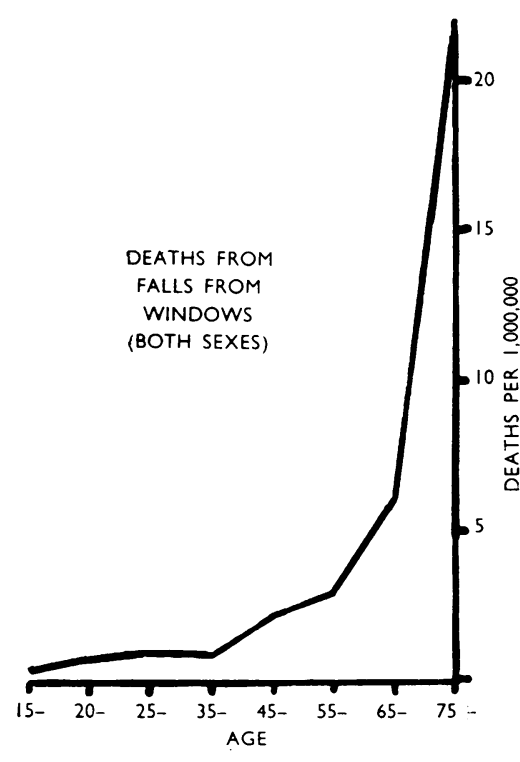

$2 a$

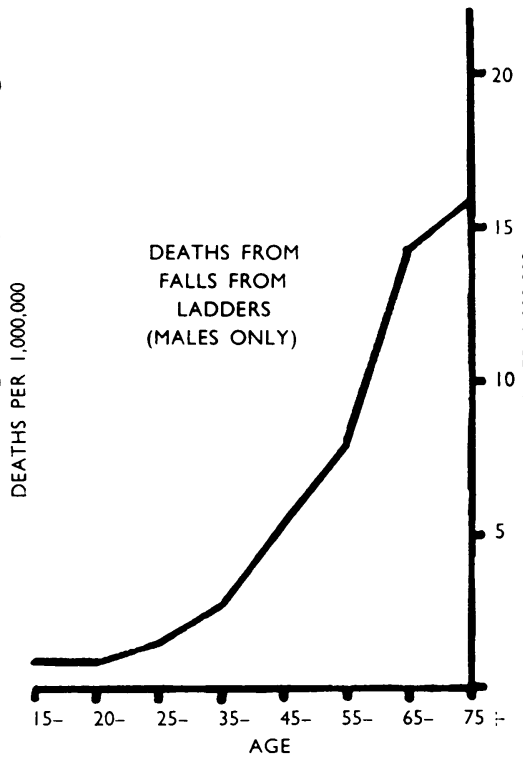

$2 b$

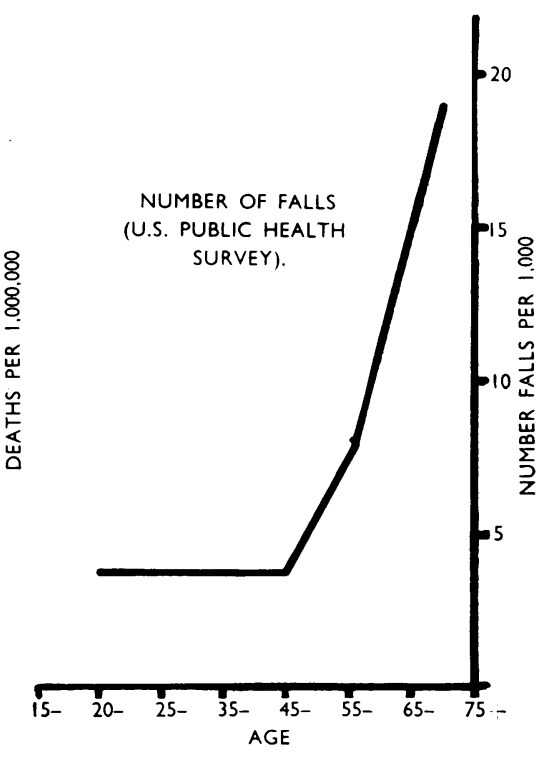

$2 c$

Fig. 2.-Fig. 2 shows (a) deaths from falls from windows per million of the population at that age, both sexes, and (b) deaths from falls from ladders per million of the population at that age, males only. (Females only constituted $\mathbf{7 \cdot 8 \%}$ of the total deaths from falls from ladders.)

These figures are arrived at by averaging the number of deaths from these causes for the years 1946, 1947, and 1948 as

given in the Registrar General's Statistical Review of England and Wales for these years, and stating them in terms of the average population at each age for this period.

Fig. 2 (c) shows the number of falls reported per 1,000 of a sample taken in each age group in the U.S. Public Health Survey (Collins, 1935). 
time lost, although permanently incapacitating injuries and deaths, whose incidence is known to rise with age, are excluded.

From the standpoint of time lost, changes in the severity of accidents with age need to be seen in the context of general health changes, and of the time lost from all health causes. Older persons lose more time through all sickness causes than do young workers (e.g., Roberts, 1951), but the actual proportion of time lost due to accidents as against other reasons appears to be fairly small, perhaps about $10 \%$ (Vernon, 1920 ; Padley, 1947). Although this relationship may change to some extent as a result of improved methods of medical treatment and extended health services, the greater the age disparity of sickness rates, the greater will be the difference in the amount of exposure to risk of accident.

\section{Type of Injury}

From the data on 5,000 compensation cases given by Stevens (1929) it is possible to calculate the proportions at different ages of certain grouped types of injury. The proportion of cuts, punctures, and lacerations $(1,711$ cases $)$ is seen to fall steadily from over $50 \%$ in the $15-19$ group to $25 \%$ in the over-60s, while the proportion of schedule losses * (707 cases) rises from $8 \%$ in the youngest to $28 \%$ in the oldest age group; there are no significant trends among the remaining injury groups. Barkin's (1933) study of compensated accidents showed a steady decline with age in the proportions of cases of crushing injuries, cuts and punctures, and lacerations. These declines he attributed to increased mastery of tools and greater care among the older workers, while brittleness of bone is suggested as the explanation of a rise with age in the proportion of injuries due to fractures. The proportion of bruises increased markedly at age 33 while that of burns and scalds decreased.

Padley (1947) observed a striking increase with age, particularly at ages above 45 , in the proportion of fractures incurred by single women, although the men showed no significant increase. Possible explanations suggested were a higher occupational risk, due to selection of types of work among the older women, or a generalized physiological sex difference, perhaps related to the menopause. Whatever the real reason, the possible role of occupational hazards as determinants of types of injury incurred cannot be ignored. Clearly there is a relationship between the type of work and the most likely kind of injury as a result of an accident. An example is

\footnotetext{
* Certain serious injuries which had been standardized for " days lost" by the Compensation Board regardless of the actual time needed for recovery.
}

quoted by Newbold (1926) who found that in making tin boxes accidents arose mainly from contact with sharp edges of the tin.

From these studies it would appear that the liability to incur certain types of injury or to be prone to those accidents which tend to produce particular kinds of injury, does in fact vary with age, but the findings are insufficiently established and further work is needed.

At present, how far this kind of variation is due to changes in the individual and how far to occupational factors, is uncertain. When deteriorative changes in the individual coincide with adverse occupational factors under a particular set of working conditions a situation arises which is likely to prove very unfavourable to the older worker. An example is the case of an employee with deteriorating eyesight engaged upon work where clear and rapid vision of the machine's movement is essential to avoid injury to the fingers. On the other hand, if specific safeguards are found to be necessary to protect older workers from a particular hazard, this would be likely to have a good effect on the accident rate of all workers, even if the relative effect varied with age.

\section{Discussion}

Behind the majority of studies there seem to lie two assumptions ; (1) that there is a general age factor in accident causation, and (2) that the effect of this is seen in the accident rates calculated from compensation data or factory records.

It is hoped that the complications, for which adequate allowance has not always been made, involved in any attempt to obtain valid information from these sources have been indicated. In general, this subject calls not for the collection of massed data but rather for a more detailed approach, taking into account differences in the age-distribution of workers on different jobs, the effects of selection, the work history and experience of individuals, standards of reporting, and the types and degree of hazard of the work.* Unless this is done, it is very difficult to say how far the calculated rates for different ages do represent the direct effects of ageing.

The generally observed decline with age in accident frequency has usually been attributed to increased experience, or greater carefulness, among the older workers. Newbold (1926) noted that it was " a generally accepted opinion that older people are more careful than younger ones ", and also drew

\footnotetext{
* Basically the problem is that of control of length of exposure ; the information mentioned is necessary if this is to be adequately achieved.
} 
a distinction between "general immaturity" and " unfamiliarity to a particular job". Sutherland and others (1950) suggested, among other things, that older workers had developed greater responsibility, while Mann (1944) claimed that the effect of monotony was greater among youthful workers, and Barkin (1933) commented on the older workers' greater capability in handling tools. While these points are general and not the results of a full analysis, they do express common opinions regarding changes with age which could be supposed to have an effect on accident liability. It is both possible and desirable to examine these suggestions in greater detail.

First, studies often show a very high number of accidents occurring among the under- 30 s compared with the rate in persons of higher ages, among whom there may be very little change. Although such a frequency distribution might give a negative correlation of accident rate with age, this would be due more to the deleterious effect of youth than to the beneficial effect of a continuous ageing process. The very high accident rate commonly found among persons who are in their first few months at a job indicates that lack of experience of the work is largely responsible for an excess of accidents among the young, but also involved may be general personality factors, such as would appear to be included in the concepts of "general immaturity" and "less responsibility". An interesting link with this is Banister's enquiry (1938) into accident causation; he listed eight main causes, among which were the meeting of a slightly novel situation in a maladaptive way, and the taking of realized risks through bravado or laziness. He comments that the latter is more common among younger workers. The longer a worker has been engaged upon an operation, the more likely he is to have met the possible variations of the normal situation and to have found appropriate ways of dealing with them. Young workers will have had less time to experience such variations, and the effect of this is the greater because of the relatively high rate of labour turnover among young employees (Kitson, 1925; Greystoke and others, 1952). It is also to be expected that, provided a person has capabilities sufficient to meet the demands of the job, as time goes on he will become more proficient through the refining of performance to meet those demands to the point of his maximum efficiency, whether the limit be imposed voluntarily or involuntarily.

Various studies, such as those reported by Welford (1951), of performance at a variety of tasks have shown that, where possible, older people take more time over each item of a task, so that in a given time they get less done but make proportionately fewer errors than younger persons. However, where performance of a task is under pressure, whether imposed by the nature of the task or constrained by the experimental instructions, older persons seem to be at a disadvantage. While it would be hazardous to transfer this finding to industry without further confirmation, since the execution of a new task for a limited time is not necessarily indicative of performance in a familiar and long-practised job, support is forthcoming from the observations made in industry by Belbin and Sewell (1949) and summarized by Welford (1951). It is perhaps also supported by the longknown fact that at times of heavy production there are often increases in the numbers of accidents, though the relative importance of the taking on of new employees and of the speed-up of work has not been determined. Although direct evidence is lacking, in situations where the worker has to keep up with a rigid time-cycle imposed by the machine, or, for other reasons, has to work at an uncongenial speed, there may be a tendency for accident frequency to rise with age.

Decline with age in various bodily functions seems likely to exert an unfavourable influence on accident liability. Where the level of a person's capabilities is reduced below that required at some stage of the work, the scene is set for a deterioration or failure in performance. The reduction of the level of capability may be very gradual and may for a time be overcome by various forms of compensation, or by the expenditure of increased effort. Eventually there may come a point at which the organism can no longer meet the demands of the situation, or can normally do so but a sudden variation or the gradually accumulating effect of fatigue causes a breakdown of performance.

Furthermore, there are also many accidents, such as falls, herniae, and those arising from " blackouts" which are not failures of performance, although they may occur in conjunction with failures of performance. As the frequency of accidents of this kind rises, often steeply, with age, the effect on the statistics of all types of accidents is to the disadvantage of the older employee.

There are, then, many factors influencing accident rates, the effects of which will vary with circumstances. Since some of these factors favour the older person and some the younger, we cannot expect that the relation between age and accident rate will always be the same. If the contentions of this article are correct, the picture which presents itself is that of two opposing tendencies : on the 
one hand, the effect of experience, greater carefulness, and so on, becoming more pronounced with age and so tending towards a lower accident rate among the older workers ; on the other hand, the biological decline of the organism as age advances. The resulting interplay issues as the observed accident rates for different ages.

In between the young and old age groups is one in whom the physical decline has not proceeded very far, but yet have considerable stability and experience and could be expected to have a lower accident rate than those at either end of the age scale. The exact shape of the accident curve will vary according to the nature and stresses of the job and the working conditions so that the older workers may have a more or less favourable accident rate according to the circumstances.

Such a picture might account for those cases where increases in accident frequency with age have been shown, as by Vernon and others (1931), since the particular sets of working conditions might have been such as to overtax the physical capacities of the older men. However, the production of more adequate statistics through a system of accident recording such as that suggested by Whitfield (1950) is essential if further light is to be thrown on this problem. An adequate record would provide information on the person injured, including occupation and department, what he was doing at the time of the accident, and the time and place of its occurrence. Objects, if any, causing the injury should be noted (a standardized classification of objects appropriate to the occupation is suggested), together with any other circumstances, such as slipping or falling, or the action of a second person. The record should also include details of the nature and location of injury, and the time lost as a result of the accident.

While this information gives as complete a picture of the accident itself as can be obtained from a record, it is not sufficient as a basis for the study of age variation. This requires the maintenance of additional records relating to ages and occupations, length of service and, so far as is possible, details of the work done while employed, and before being employed, in any particular organization for all employees and not just those who have an accident. Furthermore, details of absenteeism, whether from sickness or other causes, would enable corrections to be made for variation in the time spent at work. While the requirements listed may seem to demand a large volume of work, it may be observed that much of the information needed is often already collected under various guises, and modifications of the present system of collection might be all that would be necessary. The data provided would then permit a study of the relation between age and accident rates which at least made a more adequate allowance for the attendant circumstances than do existing studies.

\section{Summary}

The methods and results of investigations into the relation of age and industrial accident rates are surveyed and discussed. It is argued that the data at present available have serious limitations and do not permit definite conclusions as to the nature of this relationship. A detailed approach, including the collection of a number of items of information about each accident, is suggested as a prerequisite of further progress.

The authors wish to thank Professor Sir Frederic Bartlett and the Director of the Nuffield Unit, $\mathrm{Mr}$. A. T. Welford, for valuable criticism of this paper.

\section{REFERENCES}

Banister, H. (1938). Brit. J. Psychol., 28, 304.

Barkin, S. (1933). The Older Worker in Industry : Report to the Joint Legislative Committee on Unemployment. New York State. Lyon, Albany, N.Y.

Belbin, R. M., and Sewell, A. M. N. (1949). Preliminary Report on Field Studies of Ageing in Industry. Nuffield Research Unit into Problems of Ageing. Cambridge.

Brundage, D. K. (1927). Publ. Hlth. Rep., Wash., 42, 529.

Collins, S. D. (1935). Ibid., $50,1404$.

DeSilva, H. R. (1938). Sci. Mon., N.Y., 47, 536

Ghiselli, E. E., and Brown, C. W. (1948). Personnel and Industrial Psychology. McGraw Hili. New York.

, Brown, C. W., and Minium, E. W. (1946). Report to the Municipal Railway System of San Francisco.* Referred to by Ghiselli and Brown, pp. 386, 398, 412.

Greystoke, J. R., Thomason, G. F., and Murphy, T. J. (1952). J. Inst. Personn. Mgmt., 34, ij58.

Heinrich, H. W. (1950). Industrial Accident Prevention, 3rd ed. Appendix VI, p. 454. McGraw Hill, New York.

Kitson, H. D. (1925). The Psychology of Vocational Adjustment. Lippincott \& Co., Philadelphia.

Klebba, J. (1941). Publ. Hlth. Rep., Wash., 56, 2375.

Kossoris, M. D. (1940). Mon. Lab. Rev., 51, 789.

, (1948). Ibid., 67, 16.

Kuhn, H. S. (1943). Trans. Amer. Acad. Ophthal. Oto-laryng., 47, 396.

Mann, J. (1944). Industr. Med., 13, 368.

Mayer, L. M. (1937). Saf. Engng, 73, no. 3, p. 35.

Newbold, E. M. (1926). Rep. industr. Hith. Res. Board. Lond., No. 34.

Padley, R. (1947). Brit. J. soc. Med., 1, 213.

Paviere, H. D. (1951). Trans. Ass. Industr. Med. Officers, 1, 78.

Registrar General's Statistical Review of England and Wales for the Years 1946, 1947, 1948. H.M.S.O., London.
H. H.

Years 1946, 1947, 1948. H.M.S.O., London.
Roberts, C. G. (1951). Trans. Ass. industr. Med. Officers, 1, 65.

Selling, L. S. (1944). Amer. J. Orthopsychiat., 14, 276.

Sheldon, J. H. (1948). The Social Medicine of Old Age. O.U.P., London.

Simonson, E. (1947). Geriatrics, 2, 110.

Stevens, A. F. (1929). Personnel J., 8, 138.

Sutherland, I., Harris, C. G., and Smithers, A. (1950). British Journal of Industrial Medicine, 7, 140.

Vernon, H. M. (1920). Rep. industr. Hlth. Res. Board, Lond., No. 5. (1936). Accidents and their Prevention. University Press, Cambridge.

and Bedford, T. (1928). Rep. industr. Hlth. Res. Board, Lond., No. 51 .

, Bedford, T., and Warner, C. G. (1931). Ibid., No. 62

Welford, A. T. (1951). Skill and Age. (Ch. V, Ch. VII). Oxford Univ. Press, London.

Weston, H. C. (1948). Brit. J. Ophthal., 32, 645.

Whitfield, J. W. (1950). Brit. med. Bull., 7, 73.

Whitlock, J. B., and Crannell, C. W. (1949).' J. appl. Psychol., 33, 494.

* The use of test scores for the prediction of accidents of streetcar motormen. 